\title{
EN BÚSQUEDA DEL ADN Y LAS INFLUENCIAS EN ALGUNOS SISTEMAS PRESIDENCIALES Y PARLAMENTARIOS
}

JORGE CARPIZO 
SUMARIO

I. EL ADN DE LAS CONSTITUCIONES II. EL ADN DE LOS SISTEMAS PRESIDENCIALES III. EL SISTEMA PRESIDENCIAL EN LA CONSTITUCIÓN MEXICANA DE 1824 IV. LAS CONSTITUCIONES MEXICANA DE 1917 Y BRASILEÑA DE 1988 V. EL PRESIDENCIALISMO PARLAMENTARIZADO VI. LA INFLUENCIA DE LAS CONSTITUCIONES ESPAÑOLA DE 1978 Y PORTUGUESA DE 1976 VII. LA CONSTITUCIÓN FRANCESA Y LA SEGUNDA VUELTA ELECTORAL VIII. LA PERSPECTIVA ACADÉMICA**

** Agradezco a mis colegas César I. Astudillo, Enrique Cáceres, Eugenia Lizalde e Iván A. Montes Flores las sugerencias que realizaron a este ensayo. Los errores que puedan encontrarse en el mismo son responsabilidad exclusiva del autor. 


\section{EN BÚSQUEDA DEL ADN Y LAS INFLUENCIAS EN ALGUNOS SISTEMAS PRESIDENCIALES Y PARLAMENTARIOS}

POR

JORGE CARPIZO*

A don Manuel García Pelayo, ilustre constitucionalista y cientifico social de dos mundos, con invariable reconocimiento y admiración.

\section{EL ADN DE LAS CONSTITUCIONES}

1. Los avances científicos respecto al conocimiento de nuestro ADN (ácido desoxidorribonucléico) son asombrosos. Uno de ellos permite establecer que las diferencias genéticas entre los diversos grupos étnicos son mínimas; otro señala el comienzo de las migraciones desde el sureste de África hace 90,000 años, otro más precisa la identificación de los ascendientes étnicos de una persona. Queda claro que no existen grupos étnicos puros. En consecuencia, un mexicano o brasileño posee genes africanos, europeos, asiáticos e indígenas. Pero, también acontece situación similar con, por ejemplo, un escandinavo de piel blanca y cabello rubio, debido a que sus antepasados vikingos provienen del este y, con posterioridad, del norte de África, el cercano Oriente y, miles de años después, de las

* Investigador Emérito de la Universidad Nacional Autónoma de México, de la cual fue Rector, adscrito al Instituto de Investigaciones Jurídicas donde se desempeñó como Director. Presidente del Instituto Iberoamericano de Derecho Constitucional. 
relaciones que propiciaron las migraciones y el comercio con sajones, celtas, dacios, las tribus del Mar Negro y las de los nómadas de las grandes estepas.

En este sentido, qué decir de países como España e Italia; la mezcla de iberos, lusos, celtas, romanos, fenicios, árabes, normandos y judíos forma un verdadero mosaico multiétnico, por demás complejo.

Pues bien, al igual que el ADN en la persona humana se puede expresar como metáfora explicativa que las Constituciones son cuerpos normativos que no existen en forma pura, sino que han recibido, unas más que otras, múltiples influencias. A veces, hasta por contraste, en virtud de que se persigue construir sistemas de gobierno o instituciones diversas a los que se conocen, debido a que se está inconforme con aquéllos. Las ideas y los pensamientos constitucionalistas no pueden ser limitados, y con el transcurso del tiempo se han alimentado de principios, instituciones y procedimientos que se crearon en otras latitudes y que son adecuados a realidades concretas que se encuentran en constante evolución. Es, por ende, la genética constitucional.

2. Todos sabemos que una de las características del ser humano consiste en que sus conocimientos son acumulativos, susceptibles de ser corregidos y progresivos, tanto en las ciencias naturales como en las sociales y humanísticas, tanto en la física, biología, medicina o astronomía como en la filosofía, historia, economía o sociología. Lo mismo acontece con el Derecho Constitucional.

Las fuentes del Derecho Constitucional son diversas. No obstante, en la mayoría de los países del mundo, una de las importantes es la Constitución escrita que persigue primordialmente proteger y defender los derechos humanos y establecer el cauce normativo dentro del cual deben desarrollarse los fenómenos relativos al poder.

El Derecho Constitucional representa un enjambre de instituciones, valores, procesos y procedimientos, alimentados con pensamientos para alcanzar una verdadera democracia con gobernabilidad. Todos estos elementos son de naturaleza dinámica y progresiva que se dirigen a hacer frente a realidades cambiantes y diversas. El genotipo constitucional persigue clarificar cuáles son los «genes» o ascendientes de una determinada Ley Fundamental, y cuáles de esos «genes» se manifiestan constituyendo un fenotipo constitucional, como en el caso del refrendo gaditano que se incorporó en múltiples constituciones latinoamericanas.

Al continuar con la metáfora, puedo decir que el fenotipo constitucional obedece a la realidad de cada país, a su medio ambiente específico, político, histórico, social y económico ${ }^{* * *}$.

*** El genotipo es el conjunto de genes que dan identidad a una entidad como en el caso del ser humano. Ahora bien, algunos de esos genes se manifiestan y otros permanecen recesivos. Por 
La metáfora explicativa que sólo enuncio sin detenerme en ella, tal vez algún día nos conduzca a hablar de «lógica fenotípica constitucional», «medio ambiente constitucional» e incluso de "patología constitucional», entendida esta última como las mutaciones que ocurren cuando el «medio ambiente» o realidad altera el fenotipo constitucional original; es decir, el que inspiró la norma en otro país.

Hoy como nunca, debido a las nuevas tecnologías electrónicas se conocen con inmediatez, por ejemplo, las sentencias de las diversas cortes o tribunales constitucionales, las reformas a las leyes fundamentales extranjeras o la expedición de nuevas leyes.

Dicho conocimiento es enriquecedor, constituye un patrimonio constitucional, aun si no es aplicable a la realidad de otro país determinado. Son los legisladores, jueces, administradores y académicos los que han de precisar si esos pensamientos, sentencias, normas e instituciones pueden ser adoptados y adaptables con efectos positivos a su concreta circunstancia.

El Derecho Constitucional Comparado es hoy una disciplinada vigorosa, porque resulta de especial utilidad, sin olvidar jamás el contexto del país con sus múltiples peculiaridades y características propias.

\section{EL ADN DE LOS SISTEMAS PRESIDENCIALES}

1. Desarrollaré el tema de las formas o sistemas de gobierno y las influencias recíprocas entre las constituciones de seis países: tres con sistema presidencial — las del continente americano-, dos con sistema parlamentario y una con semipresidencial. Estas tres últimas corresponden a Europa. En este tema

ejemplo, un hijo tiene el cabello rubio; su madre lo tiene igualmente rubio, y negro su padre. El hijo posee en su genotipo ambos genes, pero el que se manifiesta es el de la madre. Los genes que se exteriorizan constituyen el fenotipo.

En una Constitución, entonces, el genotipo es susceptible de expresarse a través de diversos fenotipos, que corresponden a diferentes Constituciones positivas.

Bien es sabido que una institución constitucional para ser exitosa en un país tiene que adaptarse a esa realidad jurídica-política concreta o, de plano, si ello no es posible, debe desechársele en ese caso preciso. Al continuar con la metáfora, puedo decir que es algo parecido a lo siguiente: a pesar de que el genotipo de los africanos haya tenido genes de otras razas, la expresión fenotípica del color de la piel corresponde a necesidades de subsistencia bajo el sol de ese continente. Desde esta perspectiva ¿podría afirmarse que la manifestación fenotípica que tiene lugar en una Constitución, obedece a su propia supervivencia política dentro de un medio ambiente social, económico, histórico y jurídico determinado? 
específico pareciera que entre los sistemas de gobierno de los tres países americanos, Brasil, Estados Unidos y México que son presidenciales, y los europeos, España, Francia e Italia, existen distancias inalcanzables y difícilmente se pueden encontrar influencias entre ellos, pero no es así, sino todo lo contrario, lo cual es el objeto de este ensayo.

2. Las características esenciales de un sistema presidencial son tres: a) la separación de poderes entre el Legislativo y el Ejecutivo sólo es nítida desde el punto de vista que cada uno de ellos es electo por el voto popular, origen de su legitimidad, b) los periodos para los cuales son electos, tanto uno como el otro, son fijos y rígidos y, en principio, uno de ellos no puede modificar el periodo del otro, y c) entre esos dos poderes existen controles mutuos, que son diversos de aquellos que se dan en un sistema parlamentario.

3. Los originales sistemas presidenciales en América Latina nunca fueron una copia exacta del norteamericano, mucho menos en la actualidad. Éste, obviamente, influyó en forma decisiva, pero también encontramos otras ascendencias importantes.

En términos generales, el constitucionalismo latinoamericano tuvo, en sus albores, primordialmente cuatro influencias externas en la configuración de sus instituciones: la estadounidense; la española liberal proveniente de la Constitución de Cádiz, incluyendo Brasil; el pensamiento francés, en forma principal, las ideas de Rousseau, Montesquieu y Sièyes, y la de los códigos fundamentales de 1791, 1793 y 1795; e, indirectamente, la inglesa, en las obras de Locke, Blackstone y otros. En algunos documentos latinoamericanos de la época se afirma que los constituyentes tuvieron como guía a la Constitución inglesa ${ }^{1}$.

4. De los originales sistemas presidenciales latinoamericanos algunos estructuraron un presidencialismo fuerte pero se quería que fuera controlado por el congreso; otros fortalecieron el Poder Legislativo como el centro del poder, aunque posteriormente la primera corriente haya prevalecido.

Cito algunas de las fuentes que los constituyentes norteamericanos tuvieron presentes, su ADN respecto al sistema presidencial, debido a que, indirectamente, esas fuentes no son ajenas a América Latina, precisamente no lo son a través del sistema norteamericano:

1 Torre Villar, Ernesto de la y García Laguardia, Jorge Mario, Desarrollo histórico del constitucionalismo hispanoamericano, México, UNAM-Instituto de Investigaciones Jurídicas, 1976, pp. 61, 63, 142; también vale la pena examinar las pp. 37-40, 45 y 46, 51, 59-63, 136 y 137. Hernández Ruigómez, Manuel, «Las raíces históricas del presidencialismo iberoamericano», Revista Parlamentaria Iberoamericana, Madrid, 1988, núm. 7, pp. 246-248. Restrepo Piedrahita, Carlos, "El héroe del Barroco. Imagen del presidencialismo latinoamericano», Revista Parlamentaria Iberoamericana, Madrid, 1986, núm. 2, p. 71. 
a) el derecho público inglés, ya que en parte trataron de imitar, aunque deformándolo, el sistema monárquico de Inglaterra; en lugar de un jefe de Estado hereditario, se quería uno de elección popular con funciones limitadas en el tiempo.

b) La Constitución de Nueva York de 1777 y, en menor medida, la de Massachussets de 1780, que configuraron ejecutivos independientes con los rasgos principales que después estructuraron la presidencia estadounidense. A su vez, descartaron los modelos de las Constituciones de Carolina del Norte y Rhode Island, donde existieron legislativos sin mayores contrapesos ${ }^{2}$.

c) Las mencionadas obras de Locke, Montesquieu y Blackstone, en las que «el Poder Ejecutivo no está delineado en términos de suspicacia o aversión $»^{3}$, y de las cuales realizo una acotación en tres párrafos posteriores.

Sin embargo, hay que tener dos datos presentes: los constituyentes norteamericanos deseaban alejarse del modelo de la mayoría de las Constituciones de las ex-colonias, que durante 1776-1787 contaron con legislaturas sin control alguno, que aprobaban numerosas leyes con ligereza y sin cuidado, y con gobernadores débiles, cuyo periodo incluso era de sólo un año.

En cambio, en América Latina el temor fue el contrario: a la existencia de un ejecutivo muy fuerte que avasallara a los otros poderes, especialmente al legislativo. Sólo recuérdese que Simón Bolívar tuvo la idea, y la logró plasmar constitucionalmente, aunque por pocos años, de la presidencia vitalicia.

El segundo dato lo tomo de la clásica obra de Charles C. Thach: la influencia de Blackstone y Montesquieu, quienes fueron ampliamente citados en la Convención de Filadelfia, se encuentra en la idea, ampliamente arraigada en los constituyentes, de que la confusión de poderes en las mismas manos conduce a la tiranía; no obstante, no implicó una influencia determinante, porque de haber sido así, sus enseñanzas no hubieran significado una cosa en 1776: el fortalecimiento del legislativo y, otra diferente en 1787: el ejecutivo vigorizado ${ }^{4}$.

5. A su vez, existen múltiples ejemplos que verifican que los constituyentes latinoamericanos, en los albores del siglo XIX, estaban pendientes de los desarrollos políticos en los otros países de la región. Baste con mencionar los siguientes:

2 Rossiter, Clinton, The American Presidency, Nueva York, Harvest Book, 1960, p. 75.

3 Corwin, Edward S., El Poder Ejecutivo. Función y poderes 1787-1957, Buenos Aires, Bibliográfica Argentina, 1959, p. 8. Duverger, Maurice, Instituciones politicas y derecho constitucional, Barcelona, Ariel, 1962, p. 322.

${ }^{4}$ Thach, Jr., Charles C., The Creation of the Presidency, 1775-1789. A Study in Constitucional History, 3a. ed., Indianapolis, Amagi, Liberty Fund, Inc., 2007, pp. 64, 153 y 154. 
a) Muchos de los constituyentes mexicanos de 1823 y 1824 tuvieron acceso a la labor legislativa de Bolívar, como fue la Constitución de Cúcuta de 1821. El veracruzano Miguel Santa María había servido como secretario del Congreso de Cúcuta; posteriormente se desempeñó como embajador de la Gran Colombia en México.

b) El jalisciense Tadeo Ortiz escribió a Juan Martín de Pueyrredón, director supremo de Argentina, elogiando la Constitución de ese país 5 .

c) A su vez, la Constitución mexicana de 1824 influyó en varias de las leyes fundamentales de Centroamérica ${ }^{6}$ durante ese periodo.

6. La inspiración - no copia fiel- que las primeras Constituciones de los países recién independizados de la corona española en el continente americano recibieron de Estados Unidos y que se reflejó, entre otros aspectos, en la incorporación del sistema presidencial, puede considerarse lógica por las siguientes razones:

a) Todo parece indicar que el debate de la Convención de Filadelfia fue conocido por algunos constituyentes latinoamericanos ${ }^{7}$.

b) Estados Unidos fue el primer país que alcanzó su independencia en el continente, por lo cual se le admiraba; se consideraba que su Constitución aseguraba las libertades al alejarse de gobiernos monárquicos de corte absolutista, y

c) Los diplomáticos estadounidenses hicieron política activa a favor de la adopción de principios constitucionales similares a los suyos, lo cual se reforzó a partir de la doctrina Monroe, expuesta en $1823^{8}$.

7. Brasil, al independizarse, se constituyó en una monarquía parlamentaria con la Constitución de 1824. En 1891 se expidió una Constitución republicana que configuró un sistema presidencial, inspirado en el de Estados Unidos, aunque con elementos endógenos que la fueron alejando de su fuente originaria?

5 Torre Villar, Ernesto de la, Labor diplomática de Tadeo Ortiz, México, Secretaría de Relaciones Exteriores, 1974, Colección del Archivo Histórico Diplomático Mexicano, núm. 4, pp. 123 y 124.

6 Torre Villar, Ernesto de la y García Laguardia, Jorge Mario, obra citada, nota 1, pp. 107109, 123, 129-131, 137 y 138.

7 Hernández Ruigómez, Manuel, obra citada, nota 1, p. 246.

${ }^{8}$ Carpizo, Jorge, Concepto de democracia y sistema de gobierno en América Latina, México, UNAM-Instituto de Investigaciones Jurídicas, 2007, p. 52.

9 Afonso da Silva, José, "Influência, coincidência e divergência constitucionais: Espanha/Brasil», La Constitución de 1978 y el Constitucionalismo Iberoamericano, Francisco Fernández Segado, coordinador, Madrid, Centro de Estudios Políticos y Constitucionales, 2003, p. 225. 
8. La influencia española de la Constitución de Cádiz de 1812 fue muy importante en la configuración del sistema de gobierno latinoamericano, por las siguientes razones:

a) Fue una Constitución que estuvo vigente durante algunos años en América Latina, incluso en Brasil durante un día ${ }^{10}$.

b) Fue una Constitución muy conocida por los constituyentes latinoamericanos. Baste recordar que en las Cortes de Cádiz estuvieron presentes 63 diputados de las provincias de ultramar, y que algunos tuvieron intervenciones decisivas durante los debates.

c) Ex-constituyentes de Cádiz también lo fueron en las primeras asambleas constituyentes de la América Latina independiente.

d) Varias de las instituciones de Cádiz se aceptaron en las primeras Constituciones latinoamericanas, y algunas de esas instituciones persisten hasta nuestros días como el refrendo. Este aspecto lo vuelvo a aludir en párrafos posteriores al examinar la Constitución mexicana de 1824.

e) Esa Constitución representó una de las banderas del liberalismo latinoamericano y varias de sus fórmulas fueron admitidas en las primeras Constituciones de la región, tales como: la definición de nación, el concepto de soberanía nacional, los derechos de las personas y sus garantías, la situación de la religión católica. Con posterioridad, varios de estos postulados se fueron transformando ${ }^{11}$.

f) El distinguido tratadista brasileño Paulo Bonavides indica que para el constitucionalismo imperial de Brasil, la Constitución de Cádiz tuvo la misma influencia y la misma fuerza inspiradora que la Constitución norteamericana para los sistemas presidenciales de América Latina ${ }^{12}$.

${ }^{10}$ Bonavides, Paulo, «O constitucionalismo espanhol e seu influxo no Brasil (de Cádiz a Moncloa)», La Constitución de 1978 y el Constitucionalismo Iberoamericano, Francisco Fernández Segado, coordinador, Madrid, Centro de Estudios Políticos y Constitucionales, 2003, pp. 201 y 202, 218.

11 Gros Espiell, Héctor, «La Constitución española de 1978 e Iberoamérica. Evolución constitucional y proceso político democrático", La Constitución de 1978 y el Constitucionalismo Iberoamericano, Francisco Fernández Segado, coordinador, Madrid, Centro de Estudios Políticos y Constitucionales, 2003, p. 31.

12 Paulo Bonavides, obra citada, nota 10, pp. 203 y 204. 


\section{EL SISTEMA PRESIDENCIAL EN LA CONSTITUCIÓN MEXICANA DE 1824}

1. México se independizó de España en septiembre de 1821 y conoció la existencia de un gobierno imperial por breve tiempo: de 1822 a 1823 .

La Constitución mexicana de 1824 fue republicana, representativa, presidencial y federal.

No hay duda alguna que respecto al sistema de gobierno la mayor influencia fue la de la Constitución norteamericana ${ }^{13}$. Sin embargo, debe tenerse presente que Miguel Ramos Arizpe, el autor del proyecto de esa Constitución, en este punto específico, se inspiró en el documento elaborado por Esteban F. Austin, quien mezcló principios de la Constitución norteamericana y de la de Cádiz.

Austin escribió en su manuscrito que de la Constitución de Cádiz se debían copiar los artículos 133 al 139 respecto a la formación de las leyes; del 225 al 227 en lo relativo a los secretarios de Estado, y del 246 al 281 para la administración de justicia.

El proyecto de Austin estaba redactado en inglés, y entre los artículos que se tradujeron se encuentran aquellos relativos a la organización del poder ejecutivo ${ }^{14}$.

2. Los principales aspectos en los cuales la Constitución mexicana de 1824 se apartó del sistema presidencial norteamericano, y se inspiró principalmente en la Constitución española de 1812 son:

a) El refrendo, institución por medio de la cual los actos del presidente deben ser firmados por el secretario del ramo para ser válidos. A su vez, la Constitución de Cádiz había tomado esta institución de la francesa de 1791 en donde se perseguía que existiera una traba al poder del ejecutivo para expedir órdenes o decretos ${ }^{15}$ (artículo 118).

El refrendo fue aceptado en muchas de las Constituciones latinoamericanas del siglo XIX, y subsiste en la actual mexicana de 1917 y en varias otras de la región.

${ }^{13}$ Carpizo, Jorge, Estudios constitucionales, 8a. ed., México, UNAM-Instituto de Investigaciones Jurídicas y Editorial Porrúa, 2003, p. 275.

${ }^{14}$ Gaxiola, F. Jorge, "Orígenes del sistema presidencial (Génesis del acta constitutiva de 1824)», Revista de la Facultad de Derecho de México, México, tomo II, núm. 6, 1952, pp. 23 y 26-32.

15 Hauriou, Maurice, Derecho público y constitucional, Madrid, Instituto Editorial Reus, s.f., p. 448. Martínez Báez, Antonio, «El Ejecutivo y su gabinete», Revista de la Facultad de Derecho de México, México, tomo II, núm. 6, 1952, pp. 59-62. Quiroga Lavié, Humberto, Derecho constitucional latinoamericano, México, UNAM-Instituto de Investigaciones Jurídicas, 1991, p. 284. Carpizo, Jorge, El presidencialismo mexicano, 19 ed., México, Siglo Veintiuno Editores, 2006, pp. 33-36. 
b) El presidente no podía ser reelecto para el periodo inmediato, sino hasta después de que hubiesen transcurrido cuatro años de haber terminado su periodo. Este es un aspecto esencial del constitucionalismo latinoamericano y, en forma especial, del mexicano (artículo 77).

c) Las facultades del congreso y del presidente se fijaron escrupulosamente, y ninguno podía actuar más allá de las que tenía expresamente concedidas $^{16}$ (artículos 50 y 110 respectivamente).

d) El centro del poder, por el cúmulo de facultades, se encontraba en el Congreso $^{17}$. Estas facultades estaban contenidas en el artículo 50 . Además, el artículo 165 atribuyó la interpretación constitucional más relevante al propio Congreso.

e) El artículo 112 numeró con toda precisión las restricciones al presidente, lo que éste no podía realizar.

f) El presidente no tenía la facultad de indultar ${ }^{18}$; esta atribución pertenecía al Congreso (artículo 50, fracción XXV).

g) El presidente nombraba y removía libremente a los secretarios del despacho. Para su nombramiento, no necesitaba de la ratificación del Congreso y, en la propia Constitución, se estableció que la remoción era también en forma libre (artículo 110, fracción IV).

h) De acuerdo con los artículos 52, inciso 1 y 105, el presidente tenía iniciativa de ley ${ }^{19}$.

i) Los secretarios de Estado debían ser ciudadanos mexicanos por nacimiento y debían dar cuenta del estado de sus respectivos despachos a cada cámara, al comenzar sus sesiones anuales (artículos 120 y 121).

j) El sistema de responsabilidades del presidente y de sus secretarios del despacho se contemplaba en el artículo 38: cualquiera de las Cámaras podía conocer la acusación en calidad de gran jurado y por las causales —-muy amplias — señaladas en el propio artículo. Si la cámara determi-

16 Cueva, Mario de la, «La Constitución de 5 de febrero de 1857», El constitucionalismo a mediados del siglo XIX, México, UNAM-Facultad de Derecho, tomo II, 1957, pp. 1245 y 1246. Tena Ramírez, Felipe, Leyes fundamentales de México 1808-1964, 2a. ed., México, Editorial Porrúa, 1964, p. 162. Thach, Jr., Charles C., obra citada, nota 4, pp. 122 y 123, 148 y 149.

17 Reyes Heroles, Jesús, El liberalismo mexicano, tomo I, Los orígenes, México, UNAM, 1957, pp. 314 y ss. Del mismo autor y obra, tomo II, La sociedad fluctuante, México, UNAM, 1958 , p. 30.

${ }_{18}$ Carpizo, Jorge, Estudios..., obra citada, nota 13, pp. 283 y 284. Del mismo autor, El presidencialismo..., obra citada, nota 15, p. 188.

19 Véase Thach, Jr., Charles C., obra citada, nota 4, p. 156. 
naba que procedía la causa, se suspendía al presidente de su cargo y se le ponía a disposición de un tribunal.

Los secretarios del despacho eran responsables por delitos cometidos durante sus funciones.

Por lo anterior, con acierto se ha afirmado que este sistema de responsabilidades estaba inspirado más en el constitucionalismo español que en el norteamericano ${ }^{20}$.

k) Los magistrados de la Corte Suprema de Justicia eran designados por las legislaturas de los Estados, con intervención del consejo de gobierno, el congreso y, de forma particular, de la cámara de diputados.

1) El sistema de elección para el presidente y vicepresidente era indirecto. Ciertamente, estuvo inspirado en la Constitución norteamericana original, pero cuando la Constitución mexicana lo adoptó, en Estados Unidos ya no subsistía, debido a que había sido modificado en 1804 a través de la enmienda número $12^{21}$, sistema que en México resultó nefasto $^{22}$, y a lo cual me refiero con posterioridad.

3. Entre las Constituciones mexicanas de 1824, pasando por la de 1857 con las reformas de 1874, y la actual de 1917 encontramos múltiples semejanzas y numerosos artículos de 1824 que subsisten hoy en día, en lo relativo al sistema de gobierno. Quiero resaltar con la anterior afirmación que incluso en la Constitución mexicana vigente se encuentra la influencia de la Constitución de Cádiz.

\section{LAS CONSTITUCIONES MEXICANA DE 1917 Y BRASILEÑA DE 1988}

1. En principio, los sistemas presidenciales actuales de México con la Constitución de 1917, y de Brasil con la Constitución de 1988 constituyen «sistemas presidenciales puros». Lo anterior sólo quiere decir que en el sistema de controles entre el ejecutivo y el legislativo no existen mecanismos propios del sistema parlamentario.

${ }^{20}$ Mora, José María Luis, México y sus revoluciones, México, Editorial Porrúa, 1965, tomo I, pp. 286-289.

${ }^{21}$ Findlay, Bruce y Esther, Your Rugged Constitution, Stanford, California, Stanford University Press, 1969, p. 222.

${ }^{22}$ Carpizo, Jorge, Estudios..., obra citada, nota 13, p. 282. Del mismo autor, El presidencialismo..., obra citada, nota 15, pp. 63-64. 
Sin embargo, es necesario hacer dos precisiones: la primera, he manifestado en este ensayo que no existen Constituciones puras, debido a que han recibido, unas más que otras, múltiples influencias. No obstante, en este punto específico me refiero a sistema presidencial puro y ya he expuesto las diversas influencias que recibieron los sistemas norteamericano y mexicano en este aspecto. Reitero, por sistema presidencial puro se entiende únicamente que dicho sistema no contiene controles característicos del parlamentario. Al respecto, no quise cambiar la terminología y hablo de "puro» por ser la expresión técnica que emplean los tratadistas, desde Karl Loewenstein y Luis Sánchez Agesta hasta Humberto Nogueira Alcalá23.

La segunda precisión: existen mecanismos de control, cuya incorporación al sistema presidencial no implican matices parlamentarios, sino que se establecen para perfeccionar el sistema de pesos y contrapesos entre los poderes políticos, entre los cuales se pueden mencionar: el refrendo ministerial, la asistencia de los secretarios de Estado al Congreso para informar, la interpelación ministerial, la presentación de informes escritos al congreso por parte de los secretarios de Estado, la existencia de un gabinete en el que sus integrantes pueden ser removidos libremente por el presidente, comisiones legislativas de investigación e incluso la existencia de «censura» no-vinculante de los secretarios de Estado, en la cual es el criterio del presidente el que determina los efectos de la misma.

En mi opinión todos los mecanismos de control señalados en el párrafo anterior no alteran la «pureza» de un sistema presidencial.

2. En la actual Constitución brasileña de 1988, un ministro puede ser destituido si rinde informe falso al Congreso o si no informa en el plazo de 30 días a partir de que se le solicitó, de acuerdo con el inciso 2 del artículo 50. En México no existe ninguna disposición de esa naturaleza.

Dicha disposición no altera el sistema presidencial sino refuerza el régimen de responsabilidad de los funcionarios públicos, y la colaboración que debe existir entre los poderes políticos.

Ambas Constituciones, a pesar de su lejanía en el tiempo, guardan similitudes en lo concerniente al sistema presidencial. Entre las más destacadas se pueden mencionar:

${ }^{23}$ Loewenstein, Karl, «La 'presidencia' fuera de los Estados Unidos», Boletín del Instituto de Derecho Comparado de México, año II, núm. 5, 1949, pp. 22-27. Sánchez Agesta, Luis, Curso de derecho constitucional comparado, Madrid, Universidad de Madrid, Facultad de Derecho, 1976, pp. 243-245. Nogueira Alcalá, Humberto, «Tópicos sobre clasificación de los tipos de gobierno constitucionales democráticos», El derecho público a comienzos del siglo XXI. Estudios en homenaje al profesor Allan R. Brewer Carias, Madrid, Civitas, 2003, tomo I, pp. 339-345. Carpizo, Jorge, Concepto de democracia y..., obra citada, nota 8, pp. 195-197. 
a) La libertad del Presidente para nombrar y remover a los ministros o secretarios de Estado.

b) La obligación de los ministros o secretarios de Estado de brindar información en forma puntual, sobre un asunto previamente determinado, cuando alguna de las cámaras o de sus comisiones lo solicite.

c) La comparecencia de los ministros o secretarios de Estado ante las cámaras o sus comisiones, por iniciativa propia o de los legisladores, para exponer asuntos de relevancia relacionados con su ramo.

d) El sometimiento del presidente a juicio político por parte de ambas cámaras del Congreso.

e) Atribuciones de nombramiento de altos cargos, de forma compartida entre el presidente y el Senado.

f) La potestad presidencial de ejercer el veto parcial o total.

g) El sistema de comisiones de investigación.

h) El sistema de refrendo ministerial.

Algunas de las diferencias más importantes del sistema presidencial entre los dos países, las pongo de relieve en este ensayo.

3. Un principio característico del constitucionalismo latinoamericano ha sido y es la no-reelección del presidente de la república. Este principio responde a la evolución política-constitucional de la región, en donde con frecuencia el presidente encuentra los medios constitucionales o extraconstitucionales para perpetuarse en el poder.

La original Constitución mexicana de 1917 fue antireeleccionista, y después de hechos acontecidos en la década de los años veinte del siglo pasado, el presidente de la República bajo ninguna circunstancia puede reelegirse. Cumple con un periodo de seis años y jamás podrá volver a ocupar dicho cargo. Este es uno de los principios en los cuales descansa todo el sistema político mexicano ${ }^{24}$.

En Estados Unidos, en varias épocas, se ha sugerido que el presidente únicamente debe ocupar el cargo durante un solo periodo de cuatro, seis o siete años: en este sentido se han pronunciado los presidentes Andrew Jackson, An-

${ }^{24}$ Carpizo, Jorge, El presidencialismo..., obra citada, nota 15, pp. 56-59. Cosío Villegas, Daniel, La sucesión presidencial, México, Joaquín Mortiz, 1975, pp. 113, 118-120. Lerner de Sheinbaum, Bertha y Ralsky de Cimet, Susana, El poder de los presidentes. Alcances y perspectivas (19101973), México, Instituto Mexicano de Estudios Políticos, 1976, pp. 246-248. Tena Ramírez, Felipe, Derecho Constitucional Mexicano, 33 ed., México, Editorial Porrúa, 2000, p. 444. 
drew Johnson, Hayes y Taft, y Lyndon Johnson y Nixon no vieron con desagrado tal posibilidad ${ }^{25}$.

Los senadores Mike Mansfield y George Aiken también se pronunciaron por un solo periodo de seis años, considerando que esto colocaría al presidente por encima de las políticas partidistas ${ }^{26}$; desde luego que han existido críticas a esas proposiciones, tal y como también se le han hecho a la enmienda 22 que limita a dos periodos el cargo de presidente en dicho país ${ }^{27}$.

4. La Constitución brasileña de 1988 estableció que el presidente de la República no podía ser reelecto para el periodo inmediato. Esta es una fórmula que se encuentra con frecuencia en la historia y en la actualidad de América Latina.

Sin embargo, cuando un presidente tiene la fuerza o el prestigio para modificar esta fórmula, se encuentra inclinado a hacerlo; así ha acontecido y así aconteció en Brasil en 1997. Fernando Henrique Cardozo logró la reforma constitucional para permitir la reelección inmediata por una sola ocasión, la cual incluyó también a los gobernadores y los prefectos. Dicha reforma permitió a Cardozo ocupar el cargo durante dos periodos consecutivos, situación semejante a lo que acontece actualmente con el presidente Lula da Silva. Recientemente se oyeron voces de dirigentes del partido en el poder que proponían otra reforma constitucional que permitiera la reelección de Lula para un tercer periodo consecutivo. Lula expresó su oposición y consideró que una reforma constitucional que permitiera un tercer mandato sería «insensatez pura», «falta de sensibilidad política» y que "no se juega con la democracia»" ${ }^{28}$.

5. El tratadista peruano Domingo García Belaunde afirma que «la reelección inmediata en América Latina es funesta y lo demuestra la experiencia... Todos aquellos que han querido intentar la reelección desde el poder, lo que buscaban era permanecer indefinidamente. Esa es la realidad.... ${ }^{29}$. Estoy de acuerdo con el insigne autor.

El principio de no-reelección presidencial y sus modalidades continúa siendo una de las grandes cuestiones constitucionales de América Latina. Los acontecimientos y reformas constitucionales respectivas de los últimos quince años

${ }^{25}$ Schlesinger, Jr., Arthur M., The imperial presidency, Boston, Houghton Mifflin, 1973, pp. 386-387. Taft, William Howard, The president and his powers, Nueva York, Columbia University Press, 1967, p. 4. Corwin, Edward S., obra citada, nota 3, p. 39.

${ }^{26}$ Schlesinger, Jr., Arthur M., obra citada, nota 25, p. 368.

27 Sorensen, Theodore C., Watchmen in the night. Presidential accountability after Watergate, Cambridge, Massachusetts, The MIT Press, 1975, pp. 27 y 77.

${ }^{28}$ Periódico «El País», 7 de noviembre de 2007, p. 9.

29 García Belaunde, Domingo, La Constitución y su dinámica, Lima, Palestra Editores, 2006, p. 257. 
demuestran que aún no se encuentra un derrotero preciso. La norma constitucional se ha doblado ante la fuerza del titular del poder ejecutivo. Argentina, Brasil, Perú, Venezuela, Colombia, y República Dominicana pasaron de la reelección mediata a permitir la inmediata. Ecuador y Costa Rica han aceptado, en cambio, la reelección después de transcurrido un mandato presidencial, y en Costa Rica sin que se efectuara reforma constitucional alguna.

Este principio de no-reelección debe ser parte de un sistema democrático, incluso en los regímenes parlamentarios debe existir un límite a la permanencia en el poder del jefe de gobierno: ¿8, 12 o 16 años? La democracia implica también rotación en los cargos.

6. Otra característica de la Constitución mexicana de 1917 es el sistema de sustitución presidencial que establece. Todos los sistemas al respecto que conformaron las constituciones del siglo XIX fracasaron. En la realidad mexicana resultó nefasto que se conociera de antemano quien sucedería al presidente en caso de ausencia. Señalo únicamente como ejemplos que el vicepresidente Nicolás Bravo se rebeló en 1827 contra el primer presidente Guadalupe Victoria. El segundo presidente Vicente Guerrero fue derrocado por su vicepresidente Anastasio Bustamante, y así la historia prosiguió.

En la actualidad si el presidente falta, de antemano no se conoce quién lo sustituirá. En tal caso, el Congreso nombra a su sucesor de acuerdo con un sistema peculiar; designa a:

a) un presidente interino, si la falta del presidente ocurre en los dos primeros años del periodo, y el congreso expide convocatoria para la elección del presidente que debe acabar el periodo, elección que habrá de celebrarse no antes de catorce meses ni después de dieciocho a partir de la convocatoria,

a) un presidente sustituto, si la falta del presidente ocurre en los cuatro últimos años del periodo respectivo. El presidente sustituto deberá concluir éste.

a) si el congreso no se encuentra en sesiones, la comisión permanente designa a un presidente provisional y convoca a sesiones extraordinarias al congreso para que nombre un presidente interino o sustituto, según sea el caso.

Este sistema ha funcionado en tres ocasiones y bien ${ }^{30}$. No obstante, la realidad mexicana ha cambiado y en el actual sistema tripartito de partidos, en el cual tres coexisten con otros pequeños, se pudieran presentar problemas para

\footnotetext{
${ }^{30}$ Carpizo, Jorge, El presidencialismo..., obra citada, nota 15, pp. 63-69.
} 
conseguir un quórum de asistencia de las dos terceras partes del número total de los legisladores y la designación en escrutinio secreto por la mayoría absoluta de votos, sesionando las dos cámaras legislativas como un solo colegio electoral. Hay que prever esta situación para que llegado el caso, no se convierta en una crisis constitucional.

En Brasil, ante la ausencia del presidente, lo sustituye el vicepresidente.

\section{EL PRESIDENCIALISMO PARLAMENTARIZADO}

1. Bien conocido es el hecho de que más allá de las construcciones constitucionales, los presidentes latinoamericanos adquirieron una fuerza y poder extraordinarios y que, en muchas ocasiones, subordinaron a los otros poderes.

Entonces, la preocupación fue cómo limitar dicho poder y conseguir el equilibrio principalmente con el legislativo. Las fórmulas que se presentaron fueron la inclusión de algunos de los controles existentes en los sistemas parlamentarios europeos, primordialmente el español de Cádiz, el francés, levemente el inglés y, posteriormente el suizo en el caso de Uruguay. En esta forma, se fueron introduciendo de forma gradual matices o aspectos parlamentarios en América del Sur, y desde la primera mitad del siglo XIX.

2. La Constitución de Chile de 1833 diseñó un sistema presidencial, y agregó que los ministros podían simultáneamente ser legisladores, así como la facultad del congreso de acusar constitucionalmente a los ministros y destituirlos del cargo.

Al principio, la moción de censura tuvo efectos «morales», y el gabinete ministerial resistió exitosamente dichas mociones. Empero, a partir de 1871, se desarrolló una interpretación pseudoparlamentaria, creció el pluripartidismo y al vencer las fuerzas adictas a la interpretación parlamentaria de la Constitución, en la guerra civil de 1891, el Congreso estructuró la dirección del gobierno de acuerdo con las coaliciones que se formaban. De 1891 a 1924 «se produjeron ochenta y ocho cambios completos y treinta y tres cambios parciales de gabinete ministerial, pasando por el gabinete quinientas treinta personas, los ministros permanecían en sus cargos un periodo de cuatro meses» ${ }^{31}$; solamente en cinco años, hubo 18 ministros de finanzas.

31 Nogueira Alcalá, Humberto, «El sistema constitucional chileno», Los sistemas constitucionales iberoamericanos, García Belaunde, D., Fernández Segado, F. y Hernández Valle, R. (coords.), Madrid, Dykinson, 1992, pp. 276 y 277. Véase Moulin, Richard, Le présidentialisme et la classification des régimes politiques. París. Librairie Générale de Droit et de Jurisprudence, 1978, pp. 333-339. 
3. La Constitución de Perú de 1860 contuvo elementos que no son matices parlamentarios y otros que sí lo son. Entre los primeros, que se alejan del modelo de control parlamentario, se pueden mencionar los siguientes: los ministros ofrecían anualmente al congreso una memoria de su dependencia y, en cualquier tiempo, debían entregar los informes que se le solicitaran; los ministros podían presentar proyectos de ley y concurrir a los debates del Congreso, retirándose antes de la votación; aquellos podían ser interpelados por el Congreso.

$\mathrm{Al}$ mismo tiempo, dicha Constitución sí contuvo algunos matices parlamentarios; aunque no muy claros —inspirados en el modelo de Cádiz y en el francés-: el Congreso examinaba los actos del presidente al concluir el periodo constitucional, si no los aprobaba, por lesionar la Constitución o la ley, fincaba la correspondiente responsabilidad; la creación del consejo de ministros; la responsabilidad solidaria, colegiada y la individual de los ministros por los actos de su ministerio; la cámara de diputados podía entablar acusación contra uno o varios ministros en determinados $\operatorname{casos}^{32}$.

4. La Constitución de Uruguay de 1918 estableció que cualquier legislador podía solicitar a los ministros datos e informes; convocar a los ministros a las cámaras, por resolución de la tercera parte de sus miembros, con fines legislativos, de inspección o de fiscalización, y ya no por mayoría de votos como en la anterior Constitución de 1830; el Congreso podía nombrar comisiones parlamentarias de investigación; la comisión permanente podía hacer las «advertencias convenientes» al presidente, y si no surtían efecto a la segunda vez, decidía si convocaba a la asamblea general; el veto del presidente se superaba por simple mayoría si existía divergencia entre el presidente y el consejo nacional de administración, y por los tres quintos de dicha asamblea si no ocurría dicha discrepancia.

Lo sobresaliente de esta Constitución estribó en que, aunque no lo señaló expresamente, de las facultades citadas se dedujo y se creó la costumbre constitucional de la posibilidad de renuncias ministeriales «como consecuencia de votos de censura unicamerales o de declaraciones de falta de confianza ${ }^{33}$.

5. Tal y como ya asenté, considero que la interpelación al ministro o secretario de Estado no altera el régimen presidencial, sino que es un control en manos del Congreso, completamente aceptable en el sistema presidencial.

32 Ugarte del Pino, Juan Vicente, Historia de las Constituciones del Perú, Lima, Editorial Andina, 1978, pp. 434-435.

33 Gros Espiell, Héctor, Las Constituciones del Uruguay, Madrid, Centro Iberoamericano de Cooperación, 1978, p. 98. 
En América Latina, en nueve Constituciones se encuentra la figura de la interpelación: Costa Rica, El Salvador, Guatemala, Honduras, Nicaragua, Paraguay, Perú, República Dominicana y Venezuela.

De acuerdo con el artículo 165 de la Constitución de El Salvador, si un ministro, un encargado del despacho o un presidente de institución oficial autónoma no concurre a la Asamblea Legislativa a contestar las interpelaciones que se le hicieren, por este solo hecho, si no existe causa justa, queda depuesto de su cargo.

6. Por el contrario, elementos parlamentarios sí se presentan en varios países de la región. Existe la posibilidad de voto de confianza en Perú (artículo 130) y Uruguay (artículos 174 y 175) ${ }^{34}$, aunque en la realidad no suelen operar.

7. La institución de la censura se encuentra en 11 países de América Latina: Argentina (artículo 101), Colombia (artículo 135, fracciones 8 y 9), Costa Rica (artículo 121.24), Ecuador (artículo 130.9), El Salvador (artículo 165), Guatemala (artículo 167), Panamá (artículo 161.7), Paraguay (artículo 194), Perú (artículo 132), Uruguay (artículos 147 y 148) y Venezuela (artículos 240 y 246). En la recién aprobada Constitución de Bolivia, sujeta aún a referendo, se establece la censura en el artículo 159.18.

El tratadista argentino Ricardo Haro ha señalado que los artículos respectivos de Argentina, Colombia y Paraguay están inspirados en el artículo 113.1 de la Constitución española de $1978^{35}$. Cierto es que la redacción no es idéntica pero guardan rasgos similares, aunque hay que precisar que la censura no se refiere al gobierno, sino a los ministros en particular.

Otra precisión que debe asentarse: la censura no siempre trae consigo la renuncia del ministro, o para que dicha censura prospere, existen requisitos especiales.

Veamos algunos ejemplos. En Costa Rica, la Asamblea Legislativa puede "por dos tercios de votos presentes, censurar a los mismos funcionarios (ministros) cuando a juicio de la Asamblea fueren culpables de actos inconstitucionales o ilegales, o de errores graves que hayan causado o puedan causar perjuicio evidente a los intereses públicos».

Nótese que para dicha "censura» se exige una votación calificada, lo que protege a los ministros; que las causas son más de carácter penal que político; que la

${ }^{34}$ Valadés, Diego, El gobierno de gabinete, 2a. ed., México, UNAM-Instituto de Investigaciones Jurídicas, 2005, p. 65. Véase del mismo autor, La parlamentarización de los sistemas presidenciales, México, UNAM-Instituto de Investigaciones Jurídicas, 2007, pp. 43-47.

35 Haro, Ricardo, "Algunas reflexiones sobre la influencia de la Constitución española de 1978 en el constitucionalismo latinoamericano", La Constitución de 1978 y el Constitucionalismo Iberoamericano, Francisco Fernández Segado, coordinador, Madrid, Centro de Estudios Políticos y Constitucionales, 2003, p. 79. 
Asamblea goza de un amplio margen de discrecionalidad «a su juicio», y no se especifica nada más, tampoco un procedimiento, pero lo más importante, es que la censura no implica la renuncia del ministro, sobre la que el presidente de la República decide libremente.

Las Constituciones de Bolivia de 1878 y 1967 también dejaban los efectos de la censura al criterio del presidente de la República.

Ahora bien, no puede negarse que, aun en estos casos, la censura es importante y tiene efectos políticos de relevancia, ya que el presidente puede verse presionado por la opinión pública y ante la necesidad de preservar buenas relaciones con el Congreso. No obstante, la decisión última de la permanencia del ministro queda en manos del titular del Poder Ejecutivo.

En Guatemala, si el congreso emite un voto de falta de confianza a un ministro, cuando menos por la mayoría absoluta del total de los diputados, el ministro debe renunciar de inmediato. Empero, satisfaciéndose algunos requisitos, el ministro puede recurrir la falta de confianza y después de escucharlo, el congreso vuelve a votar, y para ratificar dicha falta de confianza, se necesita la votación aprobatoria de las dos terceras partes del total de los diputados que integran el congreso. Si se ratifica el voto de falta de confianza, el ministro se tiene que separar del cargo de inmediato. En cada caso, el voto de falta de confianza no puede exceder de cuatro ministros ${ }^{36}$.

La Constitución de Argentina, reformada profundamente en 1994, creó la figura de jefe de gabinete, quien es nombrado y removido por el presidente de la República, pero quien es políticamente responsable ante el congreso, que lo puede remover de su cargo por la mayoría absoluta de la totalidad de los miembros de cada cámara, sin necesidad de expresar causa. No obstante, los demás ministros no son responsables ante el congreso. En la realidad, el jefe de gabinete es un representante del presidente de la República y un "fusible», si surgen enfrentamientos graves entre los poderes políticos ${ }^{37}$.

Existe un órgano similar al gabinete en Bolivia, El Salvador, Guatemala, Honduras, Nicaragua, Paraguay, Perú, Uruguay y Venezuela que recibe la denominación de «Consejo de Ministros». En Panamá tiene la nomenclatura de "Consejo de gabinete».

7. Resulta claro y no necesita mayor comentario el distanciamiento de muchos de los sistemas presidenciales de América Latina del diseño norteamericano para ir incorporando matices o controles parlamentarios a su sistema de go-

36 Carpizo, Jorge, Concepto de democracia y..., obra citada, nota 8, p. 205.

37 Véase Planas, Pedro, Regímenes politicos contemporáneos, Lima, Fundación Friedrich Ebert, 1997, pp. 364 y 370. 
bierno, y desde fecha tan antigua como las primeras décadas del siglo XIX. En ese siglo y hasta la década de los sesenta del siglo XX, la influencia mayor en dichos matices o controles provino, como ya asenté, primordialmente de los sistemas liberal español y francés, según el país.

No obstante, en las dos últimas décadas del siglo pasado, las influencias más marcadas fueron las de las Constituciones española de 1978 e italiana de 1947, y en el caso de Brasil, en alguna manera, de la portuguesa de 1976. Al respecto algo ya he mencionado. Ahora, me ocuparé con mayor detalle de este punto.

\section{LA INFLUENCIA DE LAS CONSTITUCIONES ESPAÑOLA DE 1978 Y PORTUGUESA DE 1976}

1. España y Portugal vivieron regímenes dictatoriales a partir de la década de los años treinta del siglo XX, Portugal a principios de la década y España a finales de la misma.

América Latina, después de la segunda guerra mundial, conoció un breve periodo democrático, el cual se quebró con la llegada de dictadores y de caudillos militares al poder. En dicha área geográfica sólo podían ser considerados sistemas democráticos, en la década de los setenta, Colombia, Costa Rica y Venezuela, y la situación muy particular de México.

Portugal y España regresaron a sistemas democráticos con sus Constituciones de 1976 y 1978, respectivamente.

En América Latina, a fines de los años setenta y durante la década de los ochenta del siglo XX, los países fueron regresando a la elección libre de sus gobernantes. El retorno al sistema democrático se caracterizó por la promulgación de nuevas Constituciones o revisiones generales de las antiguas. La casi coincidencia cronológica de este retorno con la expedición de las dos Constituciones europeas mencionadas de los países más cercanos a Latinoamérica, constituyó un factor decisivo para que esta región volviera sus ojos al desarrollo constitucional ibérico.

2. En toda América Latina, incluido Brasil, el pacto de La Moncloa tuvo una repercusión política de primera magnitud. Se seguía con interés, y sintiéndolo como algo propio, el proceso de las negociaciones. Si triunfaba ese proceso en España, sería un ejemplo a seguir: transitar de la dictadura a la democracia por medio del dialogo y la negociación, evitando cualquier vestigio de violencia.

En Brasil, en 1982, el senador Fernando Henrique Cardozo, posteriormente presidente de esa nación, propuso que como el primer y gran paso hacia la democracia en ese país, se debía celebrar algo similar al Pacto de La Moncloa. 
En 2002, el candidato a la presidencia Luis Inacio Lula da Silva manifestó que perseguía un pacto social inspirado en el de La Moncloa y, ya como presidente, convocó a dicho pacto con empresarios, dirigentes sindicales y miembros de los movimientos sociales ${ }^{38}$.

En México, durante toda la transición a la democracia, se tuvo como un referente trascendente al Pacto de La Moncloa. Incluso en la actualidad, mientras los partidos políticos negocian una "Reforma del Estado", se escucha mencionar dicho Pacto como un ejemplo a seguir.

3. Respecto a la influencia de la Constitución española en América Latina, el tratadista uruguayo Héctor Gros Espiell afirma que más que contemplarla desde aspectos estrictamente jurídicos y formales, «lo más importante, lo esencial, fue el impulso democrático que generó, la esperanza que alimentó y la fe que hizo renacer en la democracia como sistema constitucional y como forma de vida política.... ${ }^{39}$.

Estoy de acuerdo con la afirmación del jurista uruguayo, pero también es importante examinar su influencia en las concepciones e instituciones concretas; a algunas ya hice alusión.

La Constitución española de 1978 inspiró principios y preceptos en las homólogas de: Argentina, Bolivia, Brasil, Colombia, Costa Rica, Ecuador, El Salvador, Guatemala, Nicaragua, Paraguay y Perú. He mencionado los países en orden alfabético.

Ahora me voy a referir a influencias concretas en temas propios o relacionados con el desarrollo de este ensayo.

4. El término Estado de Derecho era, en general, desconocido en las Constituciones latinoamericanas y más con el adjetivo de social.

El artículo 1o. de la Constitución española y su referencia puntual al Estado social y democrático de Derecho, así como su alusión al pluralismo político como valor superior, se refleja en las expresiones Estado social de Derecho y democracia pluralista de la Constitución de Paraguay; en el Estado social de Derecho de Colombia y Nicaragua, y en la aceptación del pluralismo político de Guatemala.

El preámbulo de la Constitución portuguesa de 1976 confirma la voluntad de garantizar el ejercicio de los derechos fundamentales de los ciudadanos, de establecer los principios básicos de la democracia y de asegurar el primado del Estado democrático de Derecho. De manera cercana el preámbulo de la Constitución brasileña de 1988 se refiere al Estado Democrático destinado a asegurar

\footnotetext{
38 Bonavides, Paulo, obra citada, nota 10, pp. 198, 215-219.

39 Gros Espiell, Héctor, obra citada, nota 11, pp. 38 y 39.
} 
el ejercicio de los derechos sociales e individuales, la libertad, la seguridad, el bienestar, el desarrollo, la igualdad y la justicia como valores supremos de una sociedad fraterna, pluralista y sin prejuicios. El artículo 1o. configura al pluralismo político como uno de los fundamentos del Estado democrático de Derecho, de manera similar a como lo hace la Constitución portuguesa. Las influencias de las Constituciones española y portuguesa son claras, así como de la doctrina hispánica ${ }^{40}$.

Como es natural, la Constitución brasileña de 1988 recibió mayor influencia de la portuguesa que de la española, aunque la de esta última no es de poca monta.

5. La Constitución italiana de 1947 influyó en la brasileña especialmente en lo relativo a las medidas provisionales con fuerza de ley, y a las facultades de las comisiones legislativas de investigación.

En lo referente a las medidas provisionales con fuerza de ley, el presidente las puede expedir en situaciones relevantes y urgentes. De inmediato las debe someter a la consideración del Congreso Nacional.

El artículo 62 de la Constitución brasileña señala las materias sobre las cuales no proceden esas medidas provisionales.

Dichas medidas, como regla general, pierden eficacia si no son aprobadas por el Congreso en un plazo determinado —60 días—, que excepcionalmente puede ser prorrogado.

Las dos Constituciones que vengo examinando en este apartado, más la italiana de 1947 y la alemana de 1949 jugaron un importante papel para el cambio de la metodología en esa ley fundamental brasileña al privilegiar la ubicación y la primacía de los derechos humanos, rompiendo con la clásica estructura de las Constituciones brasileñas ${ }^{41}$.

6. La Constitución española de 1978 señala en el artículo 75 que «1. Las Cámaras funcionarán en Pleno y por Comisiones. 2. Las Cámaras podrán delegar en las Comisiones Legislativas Permanentes la aprobación de proyectos o proposiciones de ley. El Pleno podrá, no obstante, recabar en cualquier momento el debate y votación de cualquier proyecto o proposición de ley que haya sido objeto de esta delegación. 3. Quedan exceptuados de lo dispuesto en el apartado anterior la reforma constitucional, las cuestiones internacionales, las leyes orgánicas y de bases y los Presupuestos Generales del Estado».

${ }^{40}$ Ibidem, p. 43. Haro, Ricardo, obra citada, nota 35, pp. 80 y 81 . Afonso da Silva, José, obra citada, nota 9, pp. 231-235.

41 Afonso da Silva, José, obra citada, nota 9, p. 236. 
Este artículo tiene marcada influencia en el precepto 79 de la Constitución argentina; alguna en el 124 de la de Costa Rica. En este último artículo es notoria la ascendencia de la Constitución italiana de $1947^{42}$.

7. El mencionado tratadista brasileño Paulo Bonavides señala que el Consejo de Desarrollo Económico y Social de ese país se creó a semejanza del español ${ }^{43}$.

8. El artículo 87.3 de la Constitución española indica que una ley orgánica regulará las formas de ejercicio y requisitos de la iniciativa popular para la presentación de proposiciones de ley; establece el número mínimo de firmas y las materias en que no procede la iniciativa popular.

Este artículo ha dejado huella en el 39 de la Constitución argentina, en los 103 y 106 de la colombiana, en el 277, inciso d) de la guatemalteca, en el 140.4 de la nicaragüense y en el 123 de la paraguaya.

9. El artículo 92, incisos 1 y 3 de la Constitución española norma que «Las decisiones políticas de especial trascendencia podrán ser sometidas a referéndum consultivo de todos los ciudadanos». La ley orgánica regula las condiciones, procedimientos y modalidades del mismo.

Este precepto ha dejado su marca en los artículos correspondientes de las Constituciones de Argentina, Colombia, Guatemala, Nicaragua y Paraguay.

10. El artículo 54 de la Constitución española configura al defensor del pueblo como un alto comisionado de las Cortes para la defensa de los derechos humanos, y con esa finalidad podrá supervisar las actividades de la administración, de lo cual rendirá cuenta a las Cortes Generales. Este artículo configura una especie de ombudsman de origen escandinavo.

Varias Constituciones latinoamericanas crearon esta institución basándose en el modelo español, desde la misma o muy parecida denominación hasta su naturaleza jurídica, aunque generalmente los preceptos constitucionales de la región latinoamericana son más amplios y precisos que el español. Tal es el caso del artículo 86 de la Constitución de Argentina, del 281 de Colombia, del 96 de Ecuador, de los 274 y 275 de Guatemala, y de los 276 a 279 de Paraguay.

11. El constitucionalismo latinoamericano de nuestros días está abierto a múltiples influencias, principalmente de Europa Occidental y del desarrollo de las propias Constituciones del área. Así, por ejemplo, se sostiene que la Constitución peruana de 1979 tiene sus influencias más claras en las Constituciones de España, Alemania, Francia e Italia y, en aspectos aislados, en las leyes

${ }^{42}$ Hernández Valle, Rubén, «Las comisiones legislativas plenas», La Constitución de 1978 y el Constitucionalismo Iberoamericano, Francisco Fernández Segado, coordinador, Madrid, Centro de Estudios Políticos y Constitucionales, 2003, pp. 337, 342 y 352.

43 Bonavides, Paulo, obra citada, nota 10, p. 219. 
fundamentales de México, Venezuela y Ecuador, amén de documentos internacionales de derechos humanos ${ }^{44}$.

12. Téngase en cuenta que en este específico tema del sistema de gobierno, en América Latina existen sistemas presidenciales de muy diversa naturaleza, y que en Europa Occidental predominan los sistemas parlamentarios, cada uno con sus propias características. En tal virtud, se podría pensar que las influencias serían escasas o de pequeña monta, lo que no es el caso. Al contrario, desde las primeras décadas del siglo XIX, y durante algunas del XX, pero especialmente a partir de la ola democratizadora de mediados de la década de los ochenta del siglo pasado en América Latina, las influencias del constitucionalismo europeo se han fortalecido, a grado tal que se puede hablar de un presidencialismo parlamentarizado, el que no deja de presentar cuestiones preocupantes.

A partir de la segunda posguerra mundial las Constituciones de Italia y Alemania fueron conocidas y comentadas en la región y, como ya asenté, la ola democratizadora de los años ochenta tuvo como paradigma primordialmente las Constituciones democráticas de España y Portugal.

Así, existe una aproximación del constitucionalismo europeo y latinoamericano respecto del sistema de gobierno, pero hay que ser cautos. En la mayoría de los países latinoamericanos los controles de naturaleza parlamentaria no se aplican en la realidad o muy excepcionalmente. A veces donde sí han funcionado, llevaron al sistema de gobierno al fracaso, como en Chile de 1891 a 1924, y en Brasil de 1961 a 1964, lo cual, a su vez, tuvo como consecuencia sendos golpes de Estado militares.

En relación con el sistema de gobierno no hay recetas. Hay que conocer bien la realidad sociopolítica del país, su historia y evolución política, y los resultados que se pretenden alcanzar.

El Derecho Comparado es un instrumento invaluable, pero debe ser utilizado con sabiduría, combinando audacia con prudencia, y jamás ignorando la realidad del país, ni los resultados precisos que se persiguen.

\section{LA CONSTITUCIÓN FRANCESA Y LA SEGUNDA VUELTA ELECTORAL}

1. En América Latina, debido principalmente a la influencia francesa de la Constitución de 1958, se ha venido aceptando que si en la votación presidencial,

${ }^{44}$ García Belaunde, Domingo, «El sistema constitucional peruano», Los sistemas constitucionales iberoamericanos, García Belaunde D., Fernández Segado, F., Hernández Valle, R., (coords.), Madrid, Dykinson, 1992, p. 698. 
ninguno de los candidatos obtiene el 50, 45 o 40\% de los votos, se realiza una segunda vuelta electoral, generalmente entre los dos candidatos que obtuvieron los mayores porcentajes del sufragio.

Actualmente, regulan la segunda vuelta las Constituciones de Argentina, Brasil, Colombia, Costa Rica, Chile, Ecuador, El Salvador, Guatemala, Nicaragua, Perú, República Dominicana y Uruguay. La recién aprobada Constitución de Bolivia, sujeta aún a referendo, también introduce este procedimiento.

El artículo 77.3 de Brasil regula lo que se puede denominar la segunda vuelta "clásica»: si ninguno de los candidatos obtiene mayoría absoluta en la primera votación, se realiza una segunda, en la cual participan los dos candidatos más votados, y se elige como presidente aquel que obtenga la mayoría de los votos válidos.

En Costa Rica el umbral de la votación no es de 50\% sino 40\%. En Argentina ese umbral es de $45 \%$ de los votos válidos o el $40 \%$ si existe una diferencia mayor de diez puntos porcentuales entre el candidato que haya alcanzado más votos y el que le sigue en segundo lugar. En Nicaragua ese umbral se fijó en 45\% de los votos.

2. En un sistema presidencial, la segunda vuelta presenta ventajas y desventajas ${ }^{45}$.

Las principales ventajas son:

a) Se refuerza la legitimidad democrática del presidente así electo, a si, por el contrario, llega al cargo, por ejemplo, con el 20, 25 o 30\% de la votación.

b) El presidente comienza su periodo con mayor representatividad y fuerza política, lo que puede aprovechar para impulsar su programa de gobierno.

c) El electorado tiene nueva oportunidad de ponderar su voto entre los dos candidatos que hubieren logrado el mayor número de aquéllos, y permite más claridad respecto a las posibilidades reales del voto.

${ }^{45}$ Carpizo, Jorge, Concepto de democracia y..., obra citada, nota 8, pp. 167-168. Nohlen, Dieter, «Sistemas electorales y sistemas de partidos en América Latina», El presidencialismo renovado. Instituciones y cambio político en América Latina, Nohlen, Dieter y Fernández B., Mario (eds.), Caracas, Nueva Sociedad, 1998, pp. 178 y 179. Valadés, Diego, «La elección del presidente como parte de la renovación presidencial», El gobierno en América Latina ipresidencialismo o parlamentarismo?, Diego Valadés y José María Serna (comps.), México, UNAM-Instituto de Investigaciones Jurídicas, 2000, pp. 240-245. Nogueira Alcalá, Humberto, obra citada, nota 31, p. 297. Shugart, Mattew Soberg y Carey, John M., Presidents and Assemblies. Constitutional Design and Electoral Dynamics, Nueva York, Cambridge University Press, 1992; pp. 209 y 210, 213-219. 
Las principales desventajas son:

a) El presidente así electo puede considerar que posee una fuerza política, de la cual carece, si su partido no cuenta con mayoría en el Congreso, y encontrarse menos inclinado a la negociación política basado en una fuerza política que puede resultar una ficción.

b) Auspicia la creación de partidos oportunistas y chantajistas, cuya única posibilidad consiste en negociar o vender su fuerza política en la segunda vuelta, sin la existencia de la cual, sería difícil que existieran.

c) Fomenta y auspicia el presidencialismo plebiscitario, fortaleciéndose el ejercicio personal del poder.

d) La gobernabilidad en un régimen presidencial se dificulta si existe un sistema exacerbado de partidos, lo que la segunda vuelta propicia.

\section{LA PERSPECTIVA ACADÉMICA}

1. Fue precisamente en la década de los setenta, cuando los sistemas antidemocráticos aumentaban en América Latina, que comenzó un gran esfuerzo editorial para impulsar el Derecho Constitucional Comparado Latinoamericano con la obra Federalismo en Latinoamérica de Jorge Carpizo. Hoy en día existen diversas publicaciones periódicas sobre esa materia, destacando el Anuario de Derecho Constitucional Latinoamericano de la Fundación Konrad Adenauer, el Anuario Iberoamericano de Justicia Constitucional del Centro de Estudios Políticos y Constitucionales de Madrid, y la Revista Latino-Americana de Estudos Constitucionais de la Universidad Federal de Ceará, Brasil ${ }^{46}$.

2. En 1974, en Buenos Aires, se creó el Instituto Iberoamericano de Derecho Constitucional que une a los constitucionalistas de América Latina, España y Portugal. Sus actividades académicas son numerosas; ha propiciado el acercamiento de los constitucionalistas de la región y, a su vez, con los de la península Ibérica; las publicaciones sobre la materia se han multiplicado; se han realizado múltiples coloquios, simposios y seminarios, entre los cuales destaca la celebración de nueve Congresos Iberoamericanos, donde se han examinado los temas más importantes para el desarrollo y fortalecimiento de la democracia y el constitucionalismo en Iberoamérica.

Además, muchos de los miembros del Instituto han tenido fuerte influencia en los desarrollos constitucionales de sus países, desde dos profesores en su cali-

${ }^{46}$ Carpizo, Jorge, Concepto de democracia y..., obra citada, nota 8, pp. 34-36. 
dad de presidentes de la República hasta incontables constituyentes, legisladores, ministros, magistrados de tribunales constitucionales o cortes supremas ${ }^{47}$.

En agosto de 2003 se fundó el Instituto Iberoamericano de Derecho Procesal Constitucional.

Muy importante resulta que los constitucionalistas agrupados en ambos Institutos, principalmente en el primero, por razones cronológicas, examinen las nuevas Constituciones o sus reformas, y la jurisprudencia constitucional de la región; propongan la incorporación de instituciones y cómo adaptarlas a la realidad, tomando en cuenta la tradición jurídica y las peculiaridades de cada país.

El conocimiento constitucional comparado de Iberoamérica nunca ha sido, en toda su historia, más difundido, profundo, útil y provechoso para el fortalecimiento de la democracia y del Estado de Derecho de esos países.

Concluyo con una precisión: en casi todos los Congresos Iberoamericanos de Derecho Constitucional han participado distinguidos catedráticos y tratadistas de: Alemania, Estados Unidos, Francia e Italia. Los enumeré en orden alfabético, y en varios también se ha contado con la presencia de académicos de Gran Bretaña y Polonia.

Ciudad Universitaria, D. F., abril de 2008.

\title{
Title
}

THE SEARCH OF THE DNA AND ITS INFLUENCE IN THE PARLIAMENTARY AND PRESIDENTIAL SYSTEMS

\begin{abstract}
Summary
I. DNA OF THE CONSTITUTIONS. II. DNA OF THE PRESIDENTIAL SYSTEMS. III. THE PRESIDENTIAL SYSTEM IN THE MEXICAN CONSTITUTION OF 1824. IV. MEXICAN AND BRAZILIAN CONSTITUTION OF 1917 AND 1988. V. PARLIAMENTARY PRESIDENCIALISM. VI. THE INFLUENCE OF THE SPANISH AND PORTUGUESE CONSTITUTIONS OF 1978 AND 1976. VII. THE FRENCH CONSITUTION AND THE SECOND ELECTORAL ROUND. VIII. ACADEMIC PERSPECTIVE.
\end{abstract}

47 Véase Carpizo, Jorge, «Treinta años del Instituto Iberoamericano de Derecho Constitucional», Instituto Iberoamericano de Derecho Constitucional 1974-2004, México, UNAM e Instituto Iberoamericano de Derecho Constitucional, 2004, 215 pp. 


\title{
Resumen
}

El trabajo examina las recíprocas influencias entre las Constituciones de seis países: tres con sistema presidencial, dos con sistema parlamentario y uno con sistema semipresidencial. Los tres últimos pertenecen a Europa.

Los sistemas presidenciales de América Latina se inspiraron en la Constitución Americana, tanto como en alguna europea, especialmente la española de 1812 .

Los enormes poderes presidenciales en América Latina llevaron a introducir en el sistema presidencial controles propios del sistema parlamentario.

\begin{abstract}
This essay tries to emphasize the reciprocal influences between the Constitutions of six countries: three with presidential systems, two with parliamentary regimes and one semi-presidential. The last three belong to Europe. The Latin American presidential systems were inspired in the American Constitution, as well as in some European, specially the Spanish Constitution of 1812. The concern to corner the enormous presidential powers in Latin America led to set to the presidential system controls pertaining to the parliamentary system. In some countries, at least in their Constitutions but not in real life, we may talk of parliamentarized presidentialism.
\end{abstract}

\section{Palabras clave}

Sistema parlamentario, sistema presidencialista, presidencialismo parlamentarizado, Derecho Constitucional Comparado.

Key words.

Presidential system, Parliamentary system, Parliamentarized presidentialism, Comparative Constitutional Law. 